\title{
Influência de Cultivares de ARRoz e Épocas da Adubação NITROGENAdA NAS RELAÇÕES DE INTERFERÊNCIA DA CULTURA COM Cultivar Simulador de INFestaçÃo de ARROZ-Vermelho ${ }^{1}$
}

\author{
Influence of Rice Cultivars and Nitrogen Fertilizer Timing on the Interference Relationships \\ Between the Crop and Cultivar Simulating Red Rice Infestation
}

\author{
AGOSTINETTO, D. ${ }^{2}$, FLECK, N.G. ${ }^{3}$, RIZZARDI, M.A. ${ }^{2}$, VIDAL, R.A. ${ }^{3}$ e COSTA, E.L.N. ${ }^{4}$
}

\begin{abstract}
RESUMO - O objetivo deste trabalho foi avaliar os efeitos de cultivares de arroz irrigado e de épocas de adubação nitrogenada durante o ciclo da cultura sobre a habilidade competitiva do cereal em relação ao cultivar EEA 406, usado como simulador da planta daninha arroz-vermelho. Para isso, conduziu-se experimento em campo, na estação de crescimento 2001/02. Os tratamentos, dispostos em esquema fatorial, constaram de cultivares de arroz (BRS-38 Ligeirinho, IRGA 417 e BR-IRGA 409), épocas de aplicação do nitrogênio (N) (100\% do $\mathrm{N}$ na semeadura, $50 \%$ do $\mathrm{N}$ na semeadura mais $50 \%$ no início da diferenciação da panícula (IDP), $100 \%$ no IDP e testemunha sem o adubo) e populações do cultivar simulador do arroz-vermelho. Para relacionar as perdas de produtividade de grãos de arroz com populações do cultivar simulador, utilizou-se o modelo de regressão da hipérbole retangular, ajustado de modo independente para os fatores estudados. Verificou-se que a época de aplicação do $\mathrm{N}$ influenciou na habilidade competitiva dos cultivares de arroz. Cultivares de ciclo muito curto e curto apresentaram maior habilidade competitiva com o cultivar simulador, quando a adubação foi realizada na semeadura, enquanto o cultivar de ciclo médio se beneficiou do fracionamento da adubação na semeadura e no IDP.
\end{abstract}

Palavras-chave: Oryza sativa, habilidade competitiva, práticas culturais, regressão não-linear.

\begin{abstract}
The objective of this study was to evaluate the effects of flooded rice cultivars and timings of nitrogen fertilizer application during the crop cycle on the competitive ability of this cereal in relation to EEA 406 cultivar, used as a mimicker of red rice. Thus, a field experiment was carried out during the 2001/02 growing season. The treatments were arranged in a factorial design,comprising the rice cultivars (BRS-38 Ligeirinho, IRGA 417, and BR-IRGA 409), nitrogen (N) application timings $(100 \%$ at sowing, $50 \%$ at sowing plus $50 \%$ at the beginning of panicle differentiation (BPD), 100\% at BPD, and check without fertilizer), and densities of the mimicker cultivar. In order to relate rice grain yield losses to densities of the mimicker cultivar, a retangular hyperbolic regression model was applied, independently adjusted for the factors tested. It was verified that $N$ application timing influenced the competitive ability of rice cultivars. Very early and early maturity rice cultivars showed greater competitive ability with mimicker genotype when $N$ fertilizer was applied at sowing time, whereas medium maturity cultivar took more advantage with $N$ fertilizer fractioning at sowing and BPD.
\end{abstract}

Key words: Oryza sativa, competitive ability, cultural practices, non linear regression.

Recebido para publicação em 30.6.2003 e na forma revisada em 18.6.2004.

2 Eng.-Agr., M.S., Aluno do Programa de Pós-Graduação em Fitotecnia da Universidade Federal do Rio Grande do Sul - UFRGS, Caixa Postal 15100, 90001-970 Porto Alegre-RS <agostinetto@agicultura.gov.br>; ${ }^{3}$ Eng.-Agr., Ph.D., Prof. da Faculdade de Agronomia da UFRGS, Bolsista do CNPq; ${ }^{4}$ Aluno do Curso de Agronomia da UFRGS, Bolsista do CNPq. 


\section{INTRODUÇÃO}

O sucesso na implementação dos programas de manejo integrado de plantas daninhas (MIPD) depende, principalmente, da habilidade em se prever, antecipadamente, a perda de produtividade da cultura devido à interferência de plantas daninhas. As estratégias utilizadas no MIPD incorporam práticas como a utilização de cultivares com maior habilidade competitiva e a época adequada para aplicação do adubo nitrogenado.

As espécies cultivadas podem expressar sua competitividade pela habilidade em suprimir as plantas daninhas ou pela habilidade em tolerar a presença dessas plantas (Jannink et al., 2000). Há indicações de que a habilidade do cultivar em suprimir as plantas daninhas possa ser mais consistente do que sua tolerância à competição. De outro modo, Lindquist \& Kropff (1996) afirmam que o aumento da tolerância da cultura às plantas daninhas auxilia o manejo, ao reduzir o impacto que cada indivíduo causa na produtividade do cultivo, resultando em aumento no número de plantas daninhas necessário para atingir o nível de dano econômico. Diversas características podem se associar à habilidade competitiva dos cultivares com plantas daninhas, dentre as quais destacam-se: velocidade de emergência, produção de massa, estatura de planta e cobertura de solo.

A competição entre a cultura do arroz irrigado e as plantas daninhas ocorre, principalmente, por nutrientes e luz. Segundo Kawano et al. (1974), sob níveis baixos de nitrogênio $(\mathrm{N})$, as plantas de arroz e as daninhas competem inicialmente pelo $\mathrm{N}$ do solo e, posteriormente, pela luz. O N é um dos principais macronutrientes necessários para o desenvolvimento normal das plantas de arroz, sendo, na maioria dos casos, o primeiro elemento a ser limitante, como resultado da competição entre cultivo e plantas daninhas (Moody, 1981).

Estudos mostram que os adubos geralmente beneficiam mais as plantas daninhas do que as cultivadas, devido à maior eficiência daquelas na absorção, no acúmulo e no uso de nutrientes (Di Tomaso, 1995). A conveniência em se aplicar adubação nitrogenada na presença de infestação de arroz-vermelho está condicionada à época, à dose e à forma de aplicação. Segundo Lopes (1991), na cultura do arroz a maior taxa de absorção do $\mathrm{N}$ ocorre entre o início do desenvolvimento das panículas e o florescimento. Quando ocorrer competição da cultura com o arroz-vermelho durante os mesmos estádios de desenvolvimento, este apresentará maior estatura, sombreando a cultura e afetando a absorção de $\mathrm{N}$ pelo arroz cultivado. De modo semelhante, Eberhardt (1998) observou que adubação nitrogenada aplicada no início da diferenciação da panícula beneficiou mais o arroz-vermelho do que o arroz cultivado.

A quantificação das perdas de produtividade da cultura, ocasionadas por uma população conhecida de plantas daninhas, normalmente é realizada pela utilização de modelos matemáticos. Esses modelos permitem simular a competição entre o cultivo e as plantas daninhas associadas, com a meta de predizer, desde períodos iniciais, a produtividade e o lucro líquido esperados em situações particulares. As funções matemáticas desenvolvidas permitem calcular niveis de dano, auxiliando na tomada de decisão para controle de plantas daninhas e, conseqüentemente, no uso mais racional dos herbicidas.

O efeito da adubação nitrogenada na interação cultura-plantas daninhas ainda é pouco conhecido, particularmente quando a época de aplicação do adubo estiver associada ao ciclo de desenvolvimento de diferentes cultivares, os quais apresentam variações na demanda desse recurso ao longo do ciclo. Assim, diferenças na época de aplicação do $\mathrm{N} \mathrm{e}$ no ciclo dos cultivares poderão constituir-se em estratégia promissora para maximizar a habilidade competitiva do arroz cultivado em relação às plantas daninhas, com prováveis vantagens na produtividade de grãos. O objetivo do presente trabalho foi avaliar o efeito de cultivares de arroz e da época de realização da adubação nitrogenada na habilidade competitiva da cultura em relação ao cultivar EEA 406, simulando infestação de arroz-vermelho.

\section{MATERIAL E MÉTODOS}

Conduziu-se experimento em campo na Estação Experimental do Arroz (EEA), pertencente ao Instituto Rio-Grandense do 
Arroz (IRGA), localizada no município de Cachoeirinha, RS, durante a estação de cultivo 2001/02. O delineamento experimental utilizado foi completamente casualizado, com uma unidade experimental por combinação de fatores. Cada unidade experimental (parcela) incluiu uma área de $10 \mathrm{~m}^{2}$. Os tratamentos foram dispostos em esquema fatorial, em que o primeiro fator constou de cultivares de arroz (BRS-38 Ligeirinho, ciclo muito curto; IRGA 417, ciclo curto; e BR-IRGA 409, ciclo médio), o segundo testou épocas de aplicação de adubo nitrogenado $(\mathrm{N}) \quad(100 \%$ do $\mathrm{N}$ incorporado na semeadura; $50 \%$ do $\mathrm{N}$ incorporado na semeadura e $50 \%$ aplicado no início da diferenciação da panícula (IDP); $100 \%$ do $\mathrm{N}$ aplicado no IDP; e sem adubação nitrogenada) e o terceiro avaliou populações (oito níveis) de plantas do cultivar de arroz EEA 406, o qual, por apresentar características morfológicas semelhantes às do arroz-vermelho, exerceu a função de simulador deste. A não-utilização do próprio arroz-vermelho como infestante natural deve-se ao nivel geralmente elevado de dormência de suas sementes (Agostinetto et al., 2001), o que leva à emergência desuniforme, dificultando o estabelecimento de populações predeterminadas no tempo e no espaço.

O preparo do solo foi realizado pelo sistema convencional. Como adubação de manutenção, utilizaram-se, na semeadura, $20 \mathrm{~kg} \mathrm{ha}^{-1}$ de $\mathrm{P}_{2} \mathrm{O}_{5}$ e $60 \mathrm{~kg} \mathrm{ha}^{-1}$ de $\mathrm{K}_{2} \mathrm{O}$, distribuídos a lanço e incorporados com grade de disco. A adubação nitrogenada foi feita de acordo com os tratamentos planejados, utilizando-se $100 \mathrm{~kg}$ de $\mathrm{N} \mathrm{ha}^{-1}$, na forma de uréia. A incorporação do adubo, nos tratamentos com aplicação na semeadura, foi efetuada junto às linhas de semeadura. A aplicação do adubo nitrogenado no estádio de IDP foi realizada a lanço e em presença de lâmina de água.

A semeadura dos cultivares foi feita em 06/11/2001, utilizando-se semeadora para experimentos, regulada para espaçamento entre linhas de $20 \mathrm{~cm}$ e densidade de semeadura de 400 sementes aptas por $\mathrm{m}^{2}$. Obteve-se população média de 329 plantas $\mathrm{m}^{-2}$. A semeadura do cultivar simulador de arroz-vermelho foi realizada em sentido transversal às linhas do arroz cultivado, no mesmo dia e com o mesmo equipamento descrito anteriormente. A irrigação por inundação foi iniciada 19 dias após a emergência (DAE) do arroz cultivado, mantendo-se uma lâmina da água de aproximadamente $10 \mathrm{~cm}$ de altura até a maturação de colheita (umidade dos grãos de $22 \%$ ). O controle de plantas daninhas e insetos-praga foi feito de acordo com as recomendações técnicas para a cultura do arroz irrigado (Embrapa, 1999).

As avaliações das populações de plantas do cultivar simulador foram realizadas aos 18 e 32 DAE, mediante contagem dos indivíduos presentes em área de $0,5 \mathrm{~m}^{2}$, subdividida em dois locais de cada parcela. A estatura de plantas foi avaliada aos 18, 32, 50 e $71 \mathrm{DAE}$, pela mensuração da parte aérea, tomada desde o nível do solo até o ápice das folhas mantidas distendidas, em 10 plantas ao acaso por parcela.

A quantificação da produtividade de grãos foi obtida pela colheita das panículas na área útil $\left(5,4 \mathrm{~m}^{2}\right)$ de cada parcela, quando o teor de umidade dos grãos de cada cultivar atingiu aproximadamente $22 \%$. A exceção a esse procedimento foi a do cultivar BRS-38 Ligeirinho, em que a área colhida variou de 0,5 a $2 \mathrm{~m}^{2}$, em razão do dano causado à parte das parcelas pelo ratão-do-banhado (Myocastor coypus), cujo ataque ocorreu a partir do estádio de IDP. Por ocasião da pesagem dos grãos, também foi determinada sua umidade, sendo os pesos corrigidos para teor de $13 \%$ de umidade.

As relações entre perdas percentuais de produtividade de grãos do arroz cultivado e populações de plantas do cultivar simulador foram determinadas separadamente para cada cultivar e época da adubação nitrogenada, ajustando-se os dados ao modelo de regressão nãolinear da hipérbole retangular, proposto por Cousens (1985).

$$
\operatorname{Pr}=\frac{(i \cdot X)}{[1+(i / a) \cdot X]}
$$

em que: $\operatorname{Pr}=$ perda de produtividade (\%); $X=$ população do cultivar simulador de arrozvermelho; $i=$ perda de produtividade $(\%)$ por unidade quando o valor da população se aproxima de zero; $a$ = perda de produtividade (\%) quando o valor da população tende ao infinito.

Planta Daninha, Viçosa-MG, v.22, n.2, p.185-193, 2004 
O ajuste dos dados ao modelo foi realizado através do procedimento Proc Nlin do programa computacional SAS (SAS, 1989). Para o procedimento de cálculos, utilizou-se o método de Gauss-Newton, o qual, por sucessivas iterações, estima os valores dos parâmetros nos quais a soma dos quadrados dos desvios das observações, em relação aos valores ajustados, seja mínima (Ratkowsky, 1983). Nos casos em que a estimativa para o parâmetro $a$ foi superestimada, o valor da assintota foi limitado para $100 \%$. Esse procedimento é recomendado quando se deseja evitar a obtenção de perdas de produtividade superiores a $100 \%$, as quais são biologicamente irreais (Yenish et al., 1997; Askew \& Wilcut, 2001). O valor da estatística $\mathrm{F}$, em nivel de $5 \%$ de probabilidade, foi utilizado como critério de ajuste dos dados ao modelo. O critério de aceitação do melhor ajuste dos dados ao modelo baseou-se no coeficiente de determinação $\left(\mathrm{R}^{2}\right)$ e na soma de quadrados do resíduo (SQR), de modo que maior valor do primeiro e menor valor do segundo representaram ajuste superior.

Os dados da variável estatura de plantas foram submetidos à análise de variância, pelo teste F. Para se proceder a comparações entre cultivares e simulador, nas médias das populações, em cada época de avaliação, utilizou-se o teste de Duncan a $5 \%$ de probabilidade.

\section{RESULTADOS E DISCUSSÃO}

O cultivar BRS-38 Ligeirinho apresentou ajuste satisfatório dos dados ao modelo, à exceção da época em que a adubação nitrogenada foi fracionada, em ambas as avaliações (Figura 1). A análise da habilidade competitiva (i) do cultivar demonstrou, de modo geral, que a adubação na semeadura aumentou a habilidade competitiva do cultivar, em relação ao cultivar competidor. O cultivo sem adição de nitrogênio, comparativamente à média dos tratamentos que receberam adubação, reduziu a habilidade competitiva do cultivar em 2,0 e 3,4 vezes na primeira e segunda épocas de avaliação, respectivamente. Verificou-se, em algumas situações de ambas as avaliações, que o modelo superestimou a perda máxima de produtividade $(a)$; nesses casos, a assintota foi limitada em $100 \%$.
Para o cultivar IRGA 417, os valores da estatística $\mathrm{F}$ foram significativos para todos os tratamentos de adubação nitrogenada, sendo geralmente satisfatório o ajuste dos dados ao modelo (Figura 2). A antecipação da adubação nitrogenada para a época da semeadura aumentou a habilidade competitiva (i) do cultivar IRGA 417, em relação ao cultivar EEA 406, simulador de arroz-vermelho. Para a maioria das estimativas realizadas, o modelo nãolinear da hipérbole retangular superestimou os valores do parâmetro $a$, o qual foi então limitado à perda máxima de produtividade de $100 \%$.

No caso do cultivar BR-IRGA 409, o ajuste dos dados ao modelo da hipérbole retangular apresentou significância estatística para todos os tratamentos de adubação nitrogenada, sendo em geral satisfatório o ajuste (Figura 3). Considerando os tratamentos que receberam adubação nitrogenada, verifica-se, de modo geral, que o fracionamento do adubo nitrogenado tendeu a aumentar a habilidade competitiva (i) do cultivar BR-IRGA 409 em relação ao cultivar simulador de arroz-vermelho. De modo geral, constatou-se que a ausência de nitrogênio reduziu a interferência do cultivar concorrente, tornando o cultivar BR-IRGA 409 potencialmente mais competitivo. De modo semelhante ao constatado para os demais cultivares, o modelo matemático utilizado superestimou a assíntota (a), necessitando-se restringi-la a $100 \%$.

Os resultados indicam que a época de aplicação do $\mathrm{N}$ tem efeito marcante no crescimento dos cultivares. A incorporação do nitrogênio quando da semeadura aumentou a habilidade competitiva dos cultivares BRS-38 Ligeirinho e IRGA 417 (Figuras 1 e 2). Comparando os tratamentos que receberam adubação nitrogenada, verifica-se que a aplicação do adubo na semeadura reduziu os valores estimados para o parâmetro $i$ em 113 e 92\% para BRS-38 Ligeirinho e em 236 e 33\% para IRGA 417, respectivamente, consideradas a primeira e segunda avaliações. Isso pode decorrer do fato de a forma de aplicação ter aumentado a disponibilidade de $\mathrm{N}$ à cultura e reduzido o suprimento para o cultivar simulador de arrozvermelho, em razão da localização do nutriente no solo, mais próximo às raízes da cultura. Resultados similares aos observados no presente 

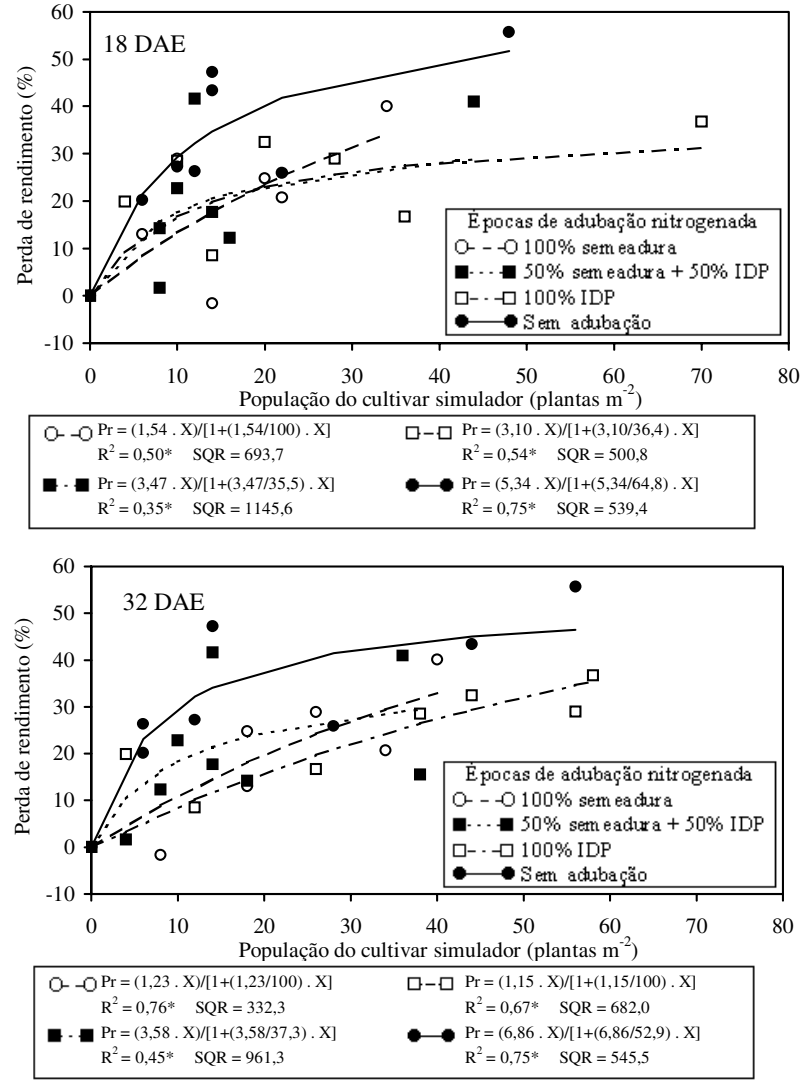

Figura 1 - Perda (\%) de produtividade (Pr) de grãos de arroz do cultivar BRS-38 Ligeirinho em função da adubação nitrogenada e da população de plantas do cultivar EEA 406, simulador de arroz-vermelho, avaliada em duas épocas. IRGA/Cachoeirinha-RS, 2001/02. (DAE = dias após emergência da cultura; IDP = início da diferenciação de panículas do arroz irrigado, com aplicação total de $100 \mathrm{~kg}$ de $\mathrm{N} \mathrm{ha}^{-1}$; * Significativo a $5 \%$ de probabilidade).

experimento foram apresentados por Di Tomaso (1995) e Eberhardt (1998). O primeiro autor observou que a aplicação do adubo junto às linhas e em profundidade aumentou a produtividade de grãos e a massa seca de feijão, bem como reduziu a massa seca das plantas daninhas associadas. Por sua vez, Eberhardt (1998) constatou que a incorporação do $\mathrm{N}$ junto às linhas de semeadura aumentou a habilidade competitiva dos cultivares de arroz avaliados, em relação ao arroz-vermelho.

Ao contrário, o cultivar BR-IRGA 409 (ciclo médio) mostrou maior habilidade competitiva quando a adubação nitrogenada foi fracionada (aplicação na semeadura e no IDP) (Figura 3). A maior habilidade competitiva demonstrada
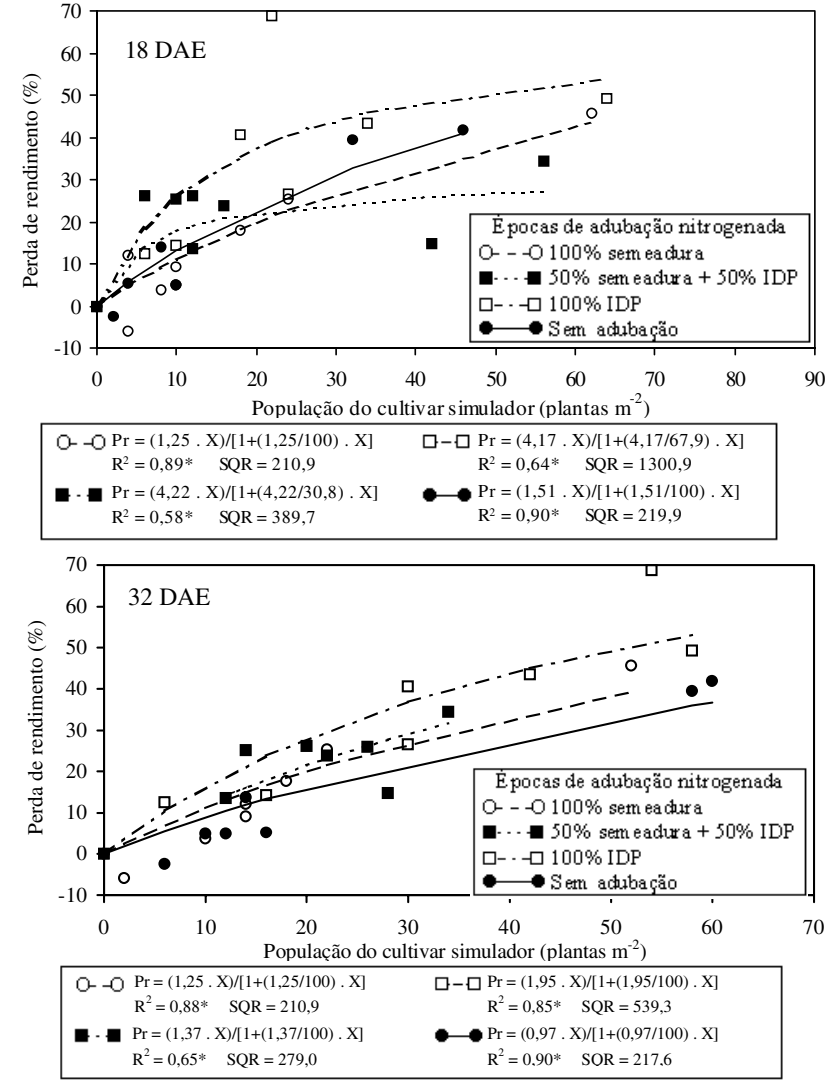

Figura 2 - Perda (\%) de produtividade (Pr) de grãos de arroz do cultivar IRGA 417 em função da adubação nitrogenada e da população de plantas do cultivar EEA 406, simulador de arroz-vermelho, avaliada em duas épocas. IRGA/ Cachoeirinha-RS, 2001/02. (DAE = dias após emergência da cultura; IDP = início da diferenciação de panículas do arroz irrigado, com aplicação total de $100 \mathrm{~kg}$ de $\mathrm{N} \mathrm{ha}^{-1}$; * Significativo a $5 \%$ de probabilidade).

pelo cultivar BR-IRGA 409 quando o adubo nitrogenado foi fracionado pode decorrer da maior disponibilidade de $\mathrm{N}$ ao longo da estação de crescimento, o que aumentaria o potencial de produtividade e o enchimento de grãos. Nesse sentido, Menezes \& Silva (1998) constataram que o cultivar de arroz BR-IRGA 410 (ciclo médio) também proporcionou vantagem competitiva em relação ao cultivar IRGA 416 (ciclo curto), quando ambos competiram com arroz-vermelho. Ainda, considerando-se a primeira avaliação, na média dos tratamentos que receberam adubação, verifica-se que o cultivar BR-IRGA 409 apresentou maior potencial competitivo com o cultivar simulador. Também, quando a adubação foi realizada de forma fracionada ou totalmente no IDP, o 
cultivar BR-IRGA 409 foi mais competitivo com o cultivar concorrente do que os outros dois, de ciclo mais curto.

Quando se comparam os cultivares quanto ao tratamento sem adubação, observa-se incremento em sua habilidade competitiva, em relação ao cultivar simulador, à medida que aumenta a duração do ciclo dos cultivares. Ou seja, o parâmetro $i$ indica que, na ausência de suplementação de nitrogênio, o cultivar BRS-38 Ligeirinho foi 4,9 e 8,4 vezes menos competitivo com o cultivar concorrente do que IRGA 417 e BR-IRGA 409, respectivamente, e que IRGA 417 foi 1,7 vez menos competitivo do que BR-IRGA 409 (Figuras 1, 2 e 3). Segundo Dhima \& Eleftherohorinos (2001), as percentagens de redução na produtividade de grãos
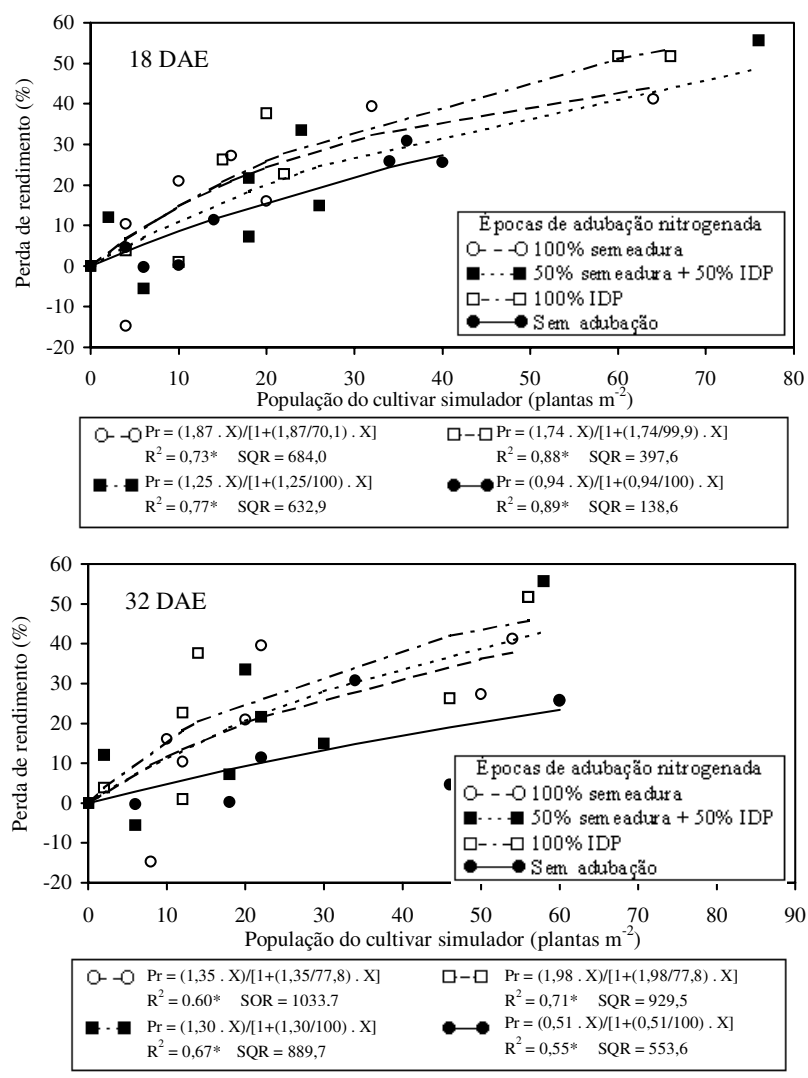

Figura 3 - Perda (\%) de produtividade (Pr) de grãos de arroz do cultivar BR-IRGA 409 em função da adubação nitrogenada e da população de plantas do cultivar EEA 406, simulador de arroz-vermelho, avaliada em duas épocas. IRGA/Cachoeirinha-RS, 2001/02. (DAE = dias após emergência da cultura; IDP = início da diferenciação de panículas do arroz irrigado, com aplicação total de $100 \mathrm{~kg}$ de $\mathrm{N} \mathrm{ha}^{-1}$; * Significativo a $5 \%$ de probabilidade). de trigo e triticale, devidas à interferência de aveia-silvestre, foram maiores quando se aplicaram $150 \mathrm{~kg}$ de $\mathrm{N}^{\text {ha }}{ }^{-1}$ do que quando não houve aplicação de N.

Na literatura, diversos trabalhos de pesquisa mencionaram que a época de aplicação do $\mathrm{N}$ afeta as relações de competição entre cultura e plantas daninhas (Watkins, 1971; Carlson \& Hill, 1986; Dhima \& Eleftherohorinos, 2001). Nesse sentido, Watkins (1971) constatou que a aplicação tardia do $\mathrm{N}$ produziu maior número de panículas em aveia-silvestre (Avena fatua), a qual concorreu mais intensamente com trigo e cevada, comparada à aplicação precoce. De modo semelhante, Carlson \& Hill (1986) observaram que aplicação de $\mathrm{N}$ tornou a aveia-silvestre mais competitiva do que o trigo, causando redução na produtividade de grãos, comparativamente ao tratamento sem nitrogênio. Também, Dhima \& Elftherohorinos (2001) relatam que o fracionamento do adubo proporcionou maior redução na produtividade de grãos em trigo e triticale competindo com aveia-silvestre do que em aplicação única incorporada.

Um estudo realizado por Cousens (1991) provê evidências de que a época relativa de desenvolvimento morfológico em cereais é crítica no resultado da competição, sendo as fases mais críticas os estádios de emergência, início do afilhamento e início e término da elongação do colmo. As duas últimas coincidem com a recomendação para aplicação fracionada do $\mathrm{N}$ em cobertura na cultura do arroz. Assim, a associação do período crítico de competição com a disponibilização de N poderá, quando da presença de plantas daninhas, agravar os efeitos negativos de sua interferência na produtividade dos cultivos.

Pelo fato de a competição por $\mathrm{N}$, entre plantas daninhas e cultivadas, não ser independente daquela por outros recursos, a habilidade do arroz irrigado em absorver e utilizar o nutriente disponivel pode incrementar sua vantagem na competição pelo recurso luz. Desse modo, a estatura de plantas é uma característica que pode relacionar-se às diferenças na capacidade competitiva dos cultivares com plantas daninhas.

No presente experimento, para todas as situações comparadas, independentemente de 
cultivar ou tratamento de adubação nitrogenada, o cultivar EEA 406 superou os demais em estatura aos 71 DAE (Tabela 1). Observouse que, em algumas situações, essa vantagem do EEA 406 ocorreu mais cedo, aos 50 DAE, como foi o caso quando toda a adubação foi aplicada na semeadura. Essa rápida resposta em crescimento do EEA 406 ao N ocorreu mesmo quando se constatou, aos $32 \mathrm{DAE}$, que cultivares como IRGA 417 e BR-IRGA 409 suplantavam o competidor em estatura.

Para BRS-38 Ligeirinho, a pior situação de competição, em termos de estatura de planta, comparativamente ao cultivar competidor, foi a aplicação de toda a adubação nitrogenada na semeadura, pois nessa condição o cultivar foi suplantado mais cedo pelo EEA 406 (Tabela 1). Quando a adubação foi dividida em duas épocas ou aplicada totalmente no IDP, o cultivar apresentou, aos 32 DAE, estatura superior à do competidor, situação que se inverteu posteriormente (71 DAE), quando se constatou maior estatura de EEA 406. Para o cultivar IRGA 417, a subdivisão do adubo nitrogenado em duas épocas, aparentemente, foi vantajosa. Já para BR-IRGA 409 toda a adubação aplicada no IDP foi favorável em relação ao competidor. Em ambas as situações de competição, o competidor apenas superou os cultivares em estatura aos 71 DAE. Cabe destacar que, nos tratamentos em que o adubo foi aplicado fracionado ou totalmente no IDP, seu efeito só pôde ser comparado em igualdade de condições na avaliação realizada aos 71 DAE.

Em geral, a adubação nitrogenada aplicada totalmente na semeadura promoveu, com maior consistência, mais o crescimento em estatura do competidor do que o dos cultivares (Tabela 1). Por outro lado, quando não houve

Tabela 1 - Estatura de planta $(\mathrm{cm})$ de cultivares de arroz e do cultivar EEA 406, simulador de arroz-vermelho, em função da adubação nitrogenada. IRGA/Cachoeirinha-RS, 2001/02

\begin{tabular}{|c|c|c|c|c|c|c|}
\hline $\mathrm{DAE}^{1 /}$ & BRS-38 & EEA 406 & IRGA 417 & EEA 406 & BR-IRGA 409 & EEA 406 \\
\hline \multicolumn{7}{|c|}{$100 \%$ semeadura } \\
\hline 18 & $27 \mathrm{a}^{*}$ & $24 \mathrm{a}$ & $25 \mathrm{a}$ & $23 \mathrm{a}$ & $23 \mathrm{~b}$ & $25 \mathrm{a}$ \\
\hline 32 & $56 \mathrm{a}$ & $55 \mathrm{a}$ & $51 \mathrm{a}$ & $45 \mathrm{~b}$ & $51 \mathrm{a}$ & $48 \mathrm{~b}$ \\
\hline 50 & $68 \mathrm{~b}$ & $82 \mathrm{a}$ & $58 \mathrm{~b}$ & $73 a$ & $64 \mathrm{~b}$ & $77 \mathrm{a}$ \\
\hline 71 & $73 \mathrm{~b}$ & $93 \mathrm{a}$ & $67 \mathrm{~b}$ & $87 \mathrm{a}$ & $73 \mathrm{~b}$ & $96 \mathrm{a}$ \\
\hline \multicolumn{7}{|c|}{$50 \%$ semeadura e $50 \%$ IDP $^{2 /}$} \\
\hline 18 & $24 \mathrm{a}$ & $25 \mathrm{a}$ & $24 \mathrm{a}$ & $26 \mathrm{a}$ & $24 \mathrm{a}$ & $23 \mathrm{a}$ \\
\hline 32 & $52 \mathrm{a}$ & $40 \mathrm{~b}$ & $46 \mathrm{a}$ & $43 \mathrm{a}$ & $48 \mathrm{a}$ & $48 \mathrm{a}$ \\
\hline 50 & $60 \mathrm{a}$ & $64 \mathrm{a}$ & $53 a$ & $59 \mathrm{a}$ & $57 \mathrm{~b}$ & $65 \mathrm{a}$ \\
\hline 71 & $67 \mathrm{~b}$ & $92 \mathrm{a}$ & $62 \mathrm{~b}$ & $83 \mathrm{a}$ & $68 \mathrm{~b}$ & $89 \mathrm{a}$ \\
\hline \multicolumn{7}{|c|}{$100 \%$ IDP } \\
\hline 18 & $21 \mathrm{a}$ & $21 \mathrm{a}$ & $21 \mathrm{a}$ & $21 \mathrm{a}$ & $20 \mathrm{a}$ & $21 \mathrm{a}$ \\
\hline 32 & $39 \mathrm{a}$ & $34 \mathrm{~b}$ & $36 \mathrm{a}$ & $35 \mathrm{a}$ & $37 \mathrm{a}$ & $35 \mathrm{a}$ \\
\hline 50 & $47 \mathrm{a}$ & $47 \mathrm{a}$ & $39 \mathrm{~b}$ & $43 \mathrm{a}$ & $42 \mathrm{a}$ & $44 \mathrm{a}$ \\
\hline 71 & $57 \mathrm{~b}$ & $78 \mathrm{a}$ & $53 \mathrm{~b}$ & $74 \mathrm{a}$ & $57 \mathrm{~b}$ & $76 \mathrm{a}$ \\
\hline \multicolumn{7}{|c|}{ Sem adubação } \\
\hline 18 & $22 \mathrm{a}$ & $22 \mathrm{a}$ & $21 \mathrm{a}$ & $21 \mathrm{a}$ & $21 \mathrm{a}$ & $23 \mathrm{a}$ \\
\hline 32 & $40 \mathrm{a}$ & $35 \mathrm{a}$ & $38 \mathrm{a}$ & $33 \mathrm{~b}$ & $39 a$ & $36 \mathrm{a}$ \\
\hline 50 & $47 \mathrm{a}$ & $48 \mathrm{a}$ & $42 \mathrm{a}$ & $42 \mathrm{a}$ & $45 \mathrm{a}$ & $47 \mathrm{a}$ \\
\hline 71 & $57 \mathrm{~b}$ & $67 \mathrm{a}$ & $48 \mathrm{~b}$ & $60 \mathrm{a}$ & $57 \mathrm{~b}$ & $67 \mathrm{a}$ \\
\hline
\end{tabular}

${ }^{1 /}$ Dias após a emergência do arroz cultivado.

2/ Início da diferenciação de panículas do arroz irrigado, com aplicação total de $100 \mathrm{~kg}$ de $\mathrm{N} \mathrm{ha}^{-1}$.

* Médias seguidas de mesma letra nas linhas, comparadas para cada cultivar e competidor, em cada época, não diferem significativamente entre si pelo teste de Duncan a 5\% de probabilidade. 
aplicação de $\mathrm{N}$, o competidor apenas superou os cultivares em estatura aos $71 \mathrm{DAE}$, em razão de características genéticas próprias de maior crescimento em estatura. Ainda, a realização da adubação nitrogenada na semeadura, ou seu fracionamento em duas épocas, aumentou a estatura média de planta dos cultivares em 30 e $28 \%$, respectivamente, comparativamente à adubação totalmente em cobertura ou à ausência de adubação nitrogenada.

Os resultados demonstram que o cultivar concorrente moldou-se às características dos cultivares de arroz. Assim, o cultivar competidor apresentou menor estatura quando em competição com o cultivar IRGA 417, o qual apresenta proporcionalmente menor estatura que os demais cultivares. Já a maior estatura de planta geralmente apresentada pelo competidor nos estádios iniciais de desenvolvimento, quando em presença do cultivar BRS-38 Ligeirinho, decorre do fato de este apresentar crescimento inicial mais rápido (ciclo muito curto), alcançando maior estatura antes dos os demais cultivares. Essa moldagem pode ser explicada pela sinalização, realizada pela radiação vermelho extrema refletida pelas folhas, da competição que ocorrerá em nivel de comunidade (Ballaré et al., 1987).

Os resultados obtidos para a estatura de planta, em resposta às épocas de aplicação do adubo nitrogenado, de modo geral não correspondem exatamente aos observados para habilidade competitiva (Figuras 1, 2 e 3). Isso pode ser atribuído ao fato de a estatura de planta ser importante somente na competição por luz, a qual afeta a produtividade dependendo do estádio em que passa a ocorrer o sombreamento, relativamente à definição dos componentes da produtividade. A razão disso é que as folhas sombreadas recebem pouca radiação direta e de maior intensidade, recebendo basicamente luz refletida e de menor intensidade, o que causará diminuição gradativa da taxa fotossintética à medida que se aproxima do solo. Assim, as folhas que se encontram sombreadas não recebem as mesmas quantidade e qualidade de luz que as localizadas no ápice do dossel.

Geralmente, a maior estatura de uma espécie propicia maior habilidade competitiva, em relação àquelas de menor porte. Segundo
Garrity et al. (1992), a estatura de planta em arroz associa-se estreitamente com a supressão de plantas daninhas; contudo, pode não ser a única característica que se relaciona, pois mesmo em cultivares de porte alto foram observadas diferenças para massa seca de plantas daninhas. Já Satorre \& Snaydon (1992) relataram existir pouca importância da estatura em definir a capacidade competitiva de cereais com plantas daninhas. Adicionalmente, Balbinot Jr. et al. (2003), em experimento com oito cultivares de arroz que apresentavam variação de ciclo, não encontraram associação entre ciclo e estatura de planta. Esses resultados corroboram os observados no presente experimento, no qual o cultivar de menor (BRS-38 Ligeirinho) e o de maior habilidade competitiva (BR-IRGA 409) apresentaram estaturas equivalentes, permitindo inferir que outras características, como duração do ciclo, afetaram mais intensamente as relações dos cultivares com o concorrente.

A maioria das inferências sobre o processo de competição do arroz cultivado com plantas daninhas decorre, basicamente, das produtividades finais dos cultivos, obtidas em experimentos com variações nas populações de plantas daninhas. Poucos são os estudos que seguem o ciclo completo de crescimento dos competidores e quantificam os efeitos da competição com base em características morfológicas de planta. Acrescente-se o fato de que a adubação nitrogenada em cobertura é uma prática cultural amplamente utilizada e que representa um componente importante do custo de produção da lavoura orizícola no Estado do Rio Grande do Sul. Nesse sentido, é importante enfatizar a contribuição desses resultados na seleção de cultivares que apresentem habilidade competitiva superior, associada à aplicação do adubo nitrogenado na época, de modo que favoreçam o desenvolvimento do arroz cultivado, posicionando-o em vantagem em relação aos seus vizinhos, potenciais concorrentes por recursos do meio.

Os resultados demonstram que a época de aplicação do adubo nitrogenado modifica a habilidade competitiva em cultivares de arroz com plantas concorrentes. Cultivares de arroz de ciclo muito curto ou curto apresentam maior habilidade competitiva com o cultivar EEA 406 quando a adubação nitrogenada é 
realizada na semeadura. O fracionamento do adubo nitrogenado na semeadura e no início da diferenciação da panícula aumenta a competitividade do cultivar de arroz de ciclo médio BR-IRGA 409 com o cultivar EEA 406. A adubação nitrogenada totalmente na semeadura ou seu fracionamento na semeadura e no início da diferenciação de panículas aumenta o crescimento em estatura de planta em cultivares de arroz.

\section{LITERATURA CITADA}

AGOSTINETTO, D. et al. Arroz-vermelho: ecofisiologia e manejo. Ci. Rural, v. 31, n. 2, p. 341-349, 2001.

ASKEW, S. D.; WILCUT, J. W. Tropic croton interference in cotton. Weed Sci., v. 49, n. 2, p. 184-189, 2001.

BALBINOT JR., A. A. et al. Competitividade de cultivares de arroz irrigado com cultivar simuladora de arroz-vermelho. Pesq. Agropec. Bras., v. 38, n. 1, p. 53-59, 2003.

BALLARÉ, C. L. et al. Early detection of neighbor plants by phytochrome perception of spectral changes in reflected sunlight. Plant Cell Environ., v. 10, n. 2, p. 551-557, 1987.

CARLSON, H. L.; HILL, J. E. Wild oat (Avena fatua) competition with spring wheat: effects of nitrogen fertilization. Weed Sci., v. 34, n. 1, p. 29-33, 1986.

COUSENS, R. An empirical model relating crop yield to weed and crop density and a statistical comparison with other models. J. Agric. Sci., v. 105, n. 3, p. 513-521, 1985.

COUSENS, R. Aspects of the design and interpretation of competition (interference) experiments. Weed Technol., v. 5, n. 3, p. 664-667, 1991.

DHIMA, K. V.; ELEFTHEROHORINOS, I. G. Influence of nitrogen on competition between winter cereals and sterile oat. Weed Sci., v. 49, n. 1, p. 77-82, 2001.

DI TOMASO, J. M. Approaches for improving crop competitiveness through the manipulation of fertilization strategies. Weed Sci., v. 43, n. 3, p. 491-497, 1995.

EBERHARDT, D. S. Manejo da adubação nitrogenada em arroz irrigado e sua relação com a competitividade do arroz-vermelho (Oryza sativa L.). 1998. $113 \mathrm{f}$. Dissertação (Mestrado em Fitotecnia) - Universidade Federal do Rio Grande do Sul, Porto Alegre, 1998.
EMBRAPA CLIMA TEMPERADO. Arroz irrigado: recomendações técnicas da pesquisa para o Sul do Brasil. Pelotas: Embrapa Clima Temperado/IRGA/EPAGRI, 1999. 124 p. (Embrapa Clima Temperado. Documento, 57).

GARRITY, D. P.; MOVILLON, M.; MOODY, K. Differential weed suppression ability in upland rice cultivars. Agron. J., v. 84, n. 4, p. 586-591, 1992.

JANNINK, J. L. et al. Index selection for weed suppressive ability in soybean. Crop Sci., v. 40, n. 4, p. 1087-1094, 2000.

KAWANO, K.; GONZALES, H.; LUCENA, M. Intraespecific competition with weeds, and spacing response in rice. Crop Sci., v. 14, n. 6, p. 841-845, 1974.

LINDQUIST, J. L.; KROPFF, M. J. Application of an ecophysiological model for irrigated rice (Oryza sativa) Echinochloa competition. Weed Sci., v. 44, n. 1, p. 52-56, 1996.

LOPES, S. I. G. Eficiência da adubação potássica e distribuição radicular do arroz irrigado. 1991. $96 \mathrm{f}$. Dissertação (Mestrado em Ciência do Solo) - Universidade Federal do Rio Grande do Sul, Porto Alegre, 1991.

MENEZES, V. G.; SILVA, P. R. F. Manejo de arroz vermelho-através do tipo e arranjo de plantas em arroz irrigado. Planta Daninha, v. 16, n. 1, p. 45-58, 1998.

MOODY, K. Weed-fertilizer interactions in rice. Manila: IRRI, 1981. 35 p. (IRRI Research Paper Series, 68).

RATKOWSKY, D. A. Nonlinear regression modeling: a unified practical approach. New York: Marcel Dekker, p. 135-154, 1983.

SAS - Institute Statistical Analysis System. User's guide: version 6. 4.ed. Cary: SAS Institute, 1989. 846 p.

SATORRE, E. H.; SNAYDON, R. W. A comparison of root and shoot competition between spring cereals and Avena fatua L. Weed Res., v. 32, n. 1, p. 45-55, 1992.

YENISH, J. P. et al. Wheat (Triticum aestivum) yield reduction from common milkweed (Asclepias syriaca) competition. Weed Sci., v. 45, n. 1, p. 127-131, 1997.

WATKINS, F. B. Effects of annual dressing of nitrogen fertilizer on wild oat infestation. Weed Res., v. 11, n. 1, p. 292-301, 1971. 